\title{
Prevalence of Adenocarcinoma of Prostate in Southern Tertiary Hospital of Nigeria from Jan.2005- Dec.2012.
}

\author{
Martin Nnoli ${ }^{1}$, Ayodele Omotosho ${ }^{1}$, Victor Nwagbara ${ }^{2}$ \\ University of Calabar Teaching hospital, Department of Pathology \& Forensic Medicine, Calabar ${ }^{l}$ \\ University of Calabar, Department of Surgery, Calabar Nigeria ${ }^{2}$
}

\begin{abstract}
:
Aim/objectives: This is to determine the frequency/age of predilection/factors that might have contributed to a particular age/range of age that is seen to be vulnerable to the lesion.

Materials and Method: A eight(8) years study of histologically diagnosed adenocarcinoma of prostate results from January, 2005-december,2012 were extracted from the departmental result register. They were a total of 330 patients were seen and analysed using SPSSversion 16.The data was presented as per age range and charts. A few of the results excluded were with no age specification - only inscribed with term 'AD' signifying Adult.

Results: From our comparison among the years of study-the age range of 60-70 years appeared to be the most frequent age affectation of the lesion when compared with all age range. This is closely followed byage range greater than 70 years. The study also showed the presence of the malignant lesion on age range of 40-50years even when one may be thinking that at this age range the prostate starts enlargement processes.

Conclusion/Recommendation: This showed the most vulnerable age range was 60-70 years as it appeared in all the year of study. This is closely followed by 70 years and above. We think that there is a great need for awareness through media education and provision of screening centres for early detection and intervention.
\end{abstract}

Keywords: Prostate, age, adenocarcinoma, histology

\section{Introduction}

Prostatic adenocarcinoma appears to be the commonest solid male genital malignancy and probably the second cause of death in Europe. ${ }^{1}$ This view is seen in the other studies like Delong champs NB et al, ${ }^{2}$ Haas et al, ${ }^{3}$ Clement $\mathrm{R},{ }^{4} \mathrm{Ojo}$ OS et al, ${ }^{5}$ Adamson AS et al. ${ }^{6}$ The Views of few of the scholars above said it is closely followed by cancer of lungs and colorectal cancer. A few risk factors have been established over the years like age of the patient, background (race), family history,obesity have been shown to contribute in formation of prostatic carcinoma. Obesity on its own have played a lot of role in formation of many malignancies. ${ }^{7,8}$ The adipose tissue in obesity patients malfunctioning has been attributed as the major cause of cancer formation. ${ }^{9}$ This adipose tissue enveloped the prostatic tissue which has a capsule like structure; as the prostate tumour infiltrates the periprostatic (PP) fat pad it resulting to closeness to the former tissue (adipose tissue). The tumour infiltrates beyond the capsule leading to the PP secreting factors with extracellular matrix/structure all causing changes in the malignant behaviours of the cells. Recent times, studies have shown that increased local production of adipokines with consequent thickness of PP fat leads to prostatic adenocarcinoma aggressiveness. $9,10,11,12,13$

The age of predilection is 55 years in blacks in most of the studies. However, most of our patients fall within and a few below this figure. ${ }^{14}$ In our study, we deem our inclusion criteria to be with ages of 40-75 years and absence of previous prostatic treatment.

Overall, the incidence rate has been variable due to a lot of factors ranging from availability of screening centre, ignorance/lack of education,genetic role and environmental factors. In most causes it is difficult to evaluate incidence rate as most of the cases are latent and detection using usual screening technique-appears in most cases not to pick the lesion. ${ }^{15}$

Despite the invention of PSA (Prostatic Specific Antigen) tumour marker and constant free health services provided by some Non-governmental organization(NGO) at times; this lesion is still been seen in early age in many asymptomatic patients. ${ }^{5,6}$ In our nation, just like other developing countries often times patients are seen at late stages with secondary metastasis which present with features of either obstructive or irritating symptoms ; at times bothfeatures could be seen co-existing inn a patient. These ranges from obstructive symptoms as dysuria, sense of residual urine, poor stream, hesitancy and intermittent dribbling. In other cases as irritating symptoms features as frequency, urgency and nocturia are seen. In most cases of metastasis are gross haematuria with either of obstructive or irritating symptoms with low back pain. ${ }^{5}$ At times this metastasis may follow lymphatic or haematogenous route with bone involvement. ${ }^{6}$ At times this metastasis will spread to the seminal vesicles, bladder and regional lymph nodes. ${ }^{7}$ 
In our study, we intend to evaluate the number of the lesions seen in our centre over a period of seven years with emphasis on the age range of occurrence and possible suggestion(s) for early investigation at any close tertiary institute to the patients-since this requires an expert management in all cases. This is to the fact that we believe that early diagnosis will lead to urgent intervention with consequencies of good prognosis in the long run.

\section{Materials And Method}

A cross sectional study of eight (8) years study of histologically diagnosed adenocarcinoma of prostate - (all stained using haematoxylin and eosin method) from January,2005 to December, 2012 were extracted from the departmental result register. A total of 330 diagnosed patient results was obtained and analysed using SPSS version 16. They were represented in data as per age ranges and chart as seen in result column.

\section{Results:}

2005

\begin{tabular}{|ll|l|l|l|l|}
\hline & & Frequency & Percent & Valid Percent & Cumulative Percent \\
\hline Valid & $50-60$ years & 8 & 8.0 & 21.6 & 21.6 \\
& 60 - 70 years & 17 & 17.0 & 45.9 & 67.6 \\
& Above 70 years & 12 & 12.0 & 32.4 & 100.0 \\
& Total & 37 & 37.0 & 100.0 & \\
Missing & System & 63 & 63.0 & & \\
Total & & 100 & 100.0 & & \\
\hline
\end{tabular}

Prevelance of Adenocarcinoma in 2005

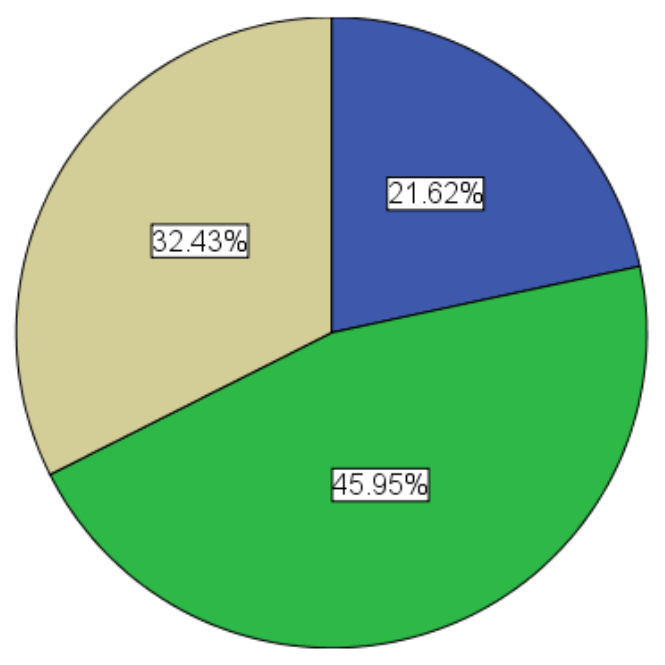

\begin{tabular}{|ll|l|l|l|l|}
\hline & & Frequency & Percent & Valid Percent & Cumulative Percent \\
\hline Valid & $20-30$ years & 1 & 1.0 & 1.8 & 1.8 \\
& $50-60$ years & 12 & 12.0 & 21.4 & 23.2 \\
& $60-70$ years & 26 & 26.0 & 46.4 & 69.6 \\
& Above 70 years & 16 & 16.0 & 28.6 & 98.2 \\
& Adult & 1 & 1.0 & 1.8 & 100.0 \\
& Total & 56 & 56.0 & 100.0 & \\
Missing & System & 44 & 44.0 & & \\
Total & & 100 & 100.0 & & \\
\hline
\end{tabular}



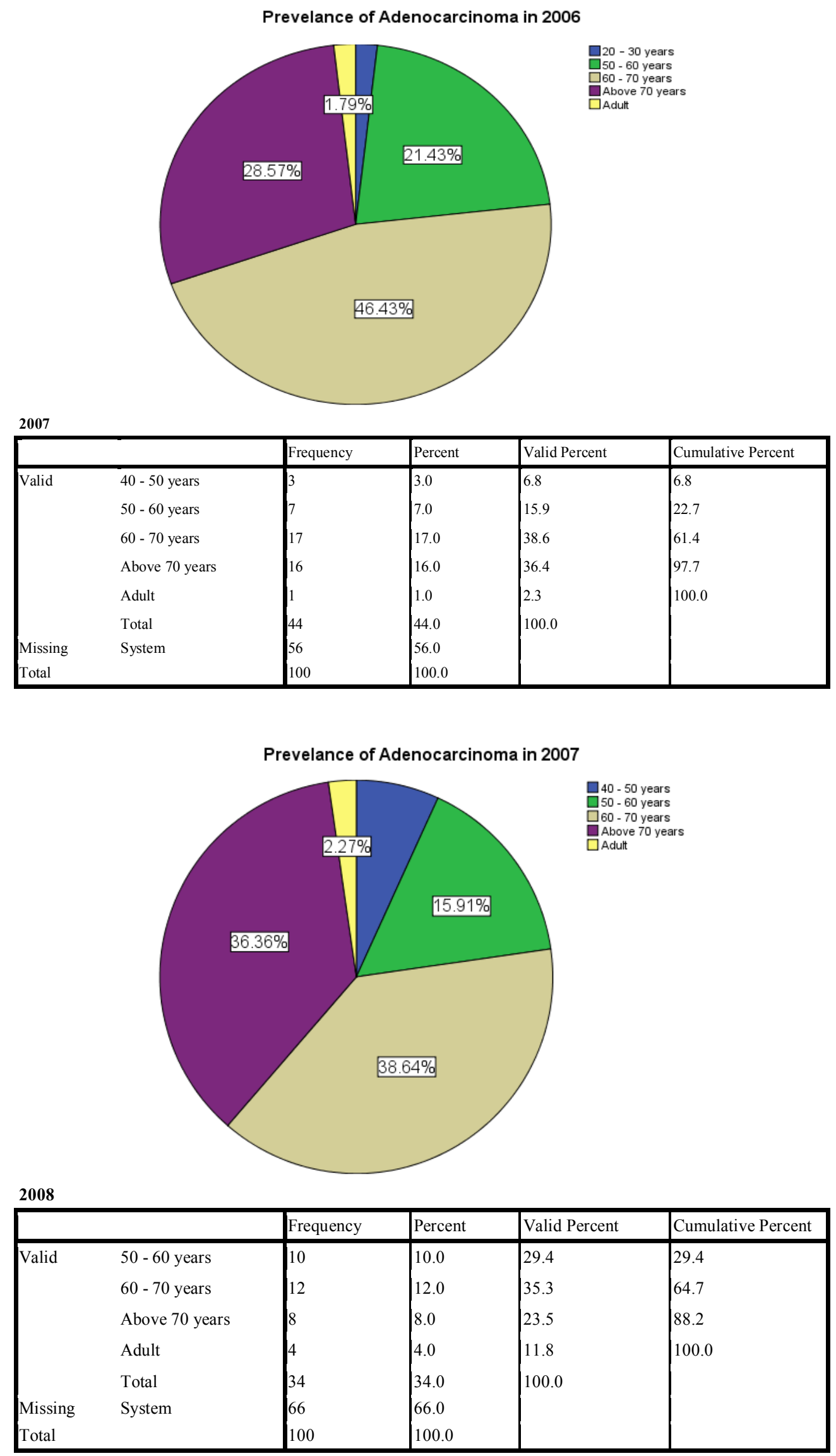

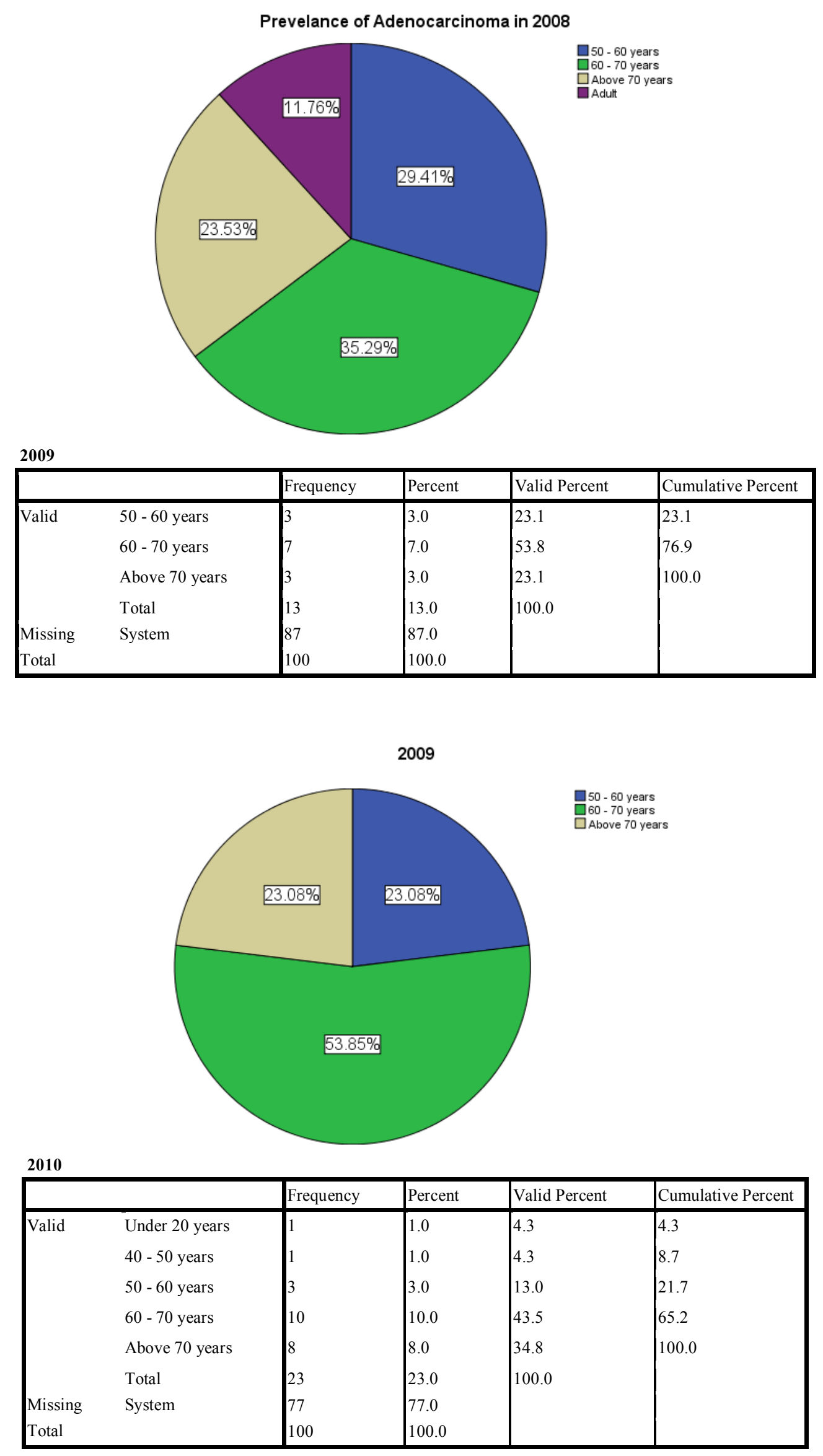


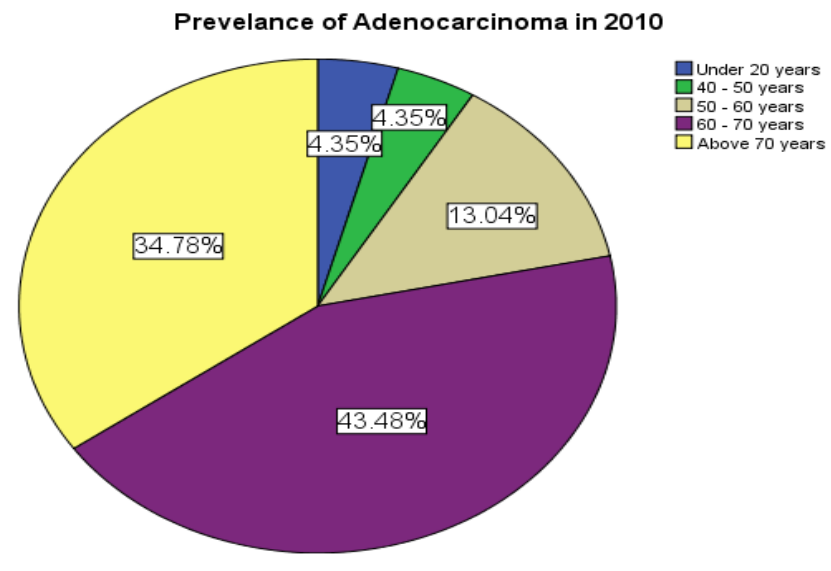

2011

\begin{tabular}{|ll|l|l|l|l|}
\hline & & Frequency & Percent & Valid Percent & Cumulative Percent \\
\hline Valid & Under 20 years & 1 & 1.0 & 1.5 & 1.5 \\
& 40 - 50 years & 4 & 4.0 & 6.1 & 7.6 \\
& $50-60$ years & 10 & 10.0 & 15.2 & 22.7 \\
& 60 - 70 years & 27 & 27.0 & 40.9 & 63.6 \\
& Above 70 years & 24 & 24.0 & 36.4 & 100.0 \\
& Total & 66 & 66.0 & 100.0 & \\
Missing & System & 34 & 34.0 & & \\
Total & & 100 & 100.0 & & \\
\hline
\end{tabular}

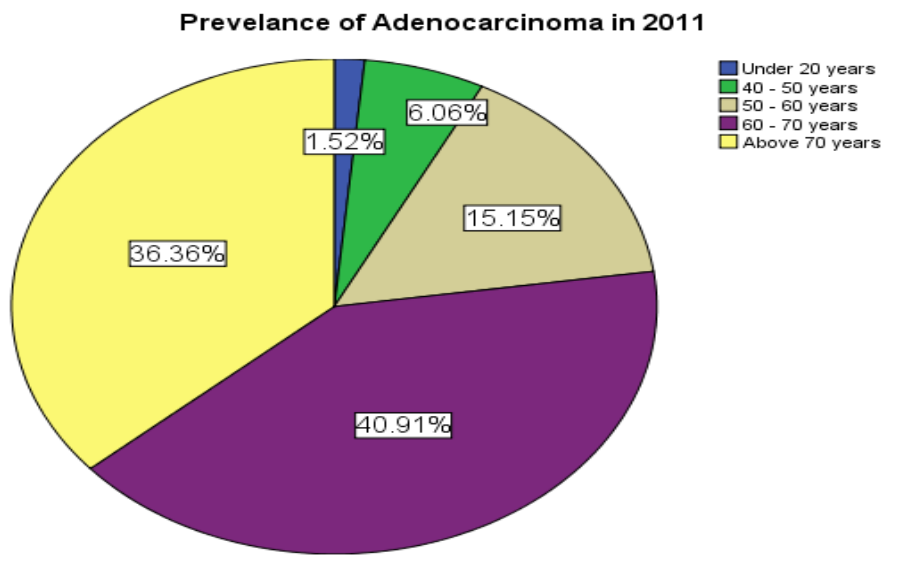

\begin{tabular}{|ll|l|l|l|l|}
\hline \multicolumn{2}{|l|}{} & Frequency & Percent & Valid Percent & Cumulative Percent \\
\hline Valid & $30-40$ years & 1 & 1.0 & 1.8 & 1.8 \\
& 40 - 50 years & 1 & 1.0 & 1.8 & 3.5 \\
& $50-60$ years & 10 & 10.0 & 17.5 & 21.1 \\
& 60 - 70 years & 27 & 27.0 & 47.4 & 68.4 \\
& Above 70 years & 17 & 17.0 & 29.8 & 98.2 \\
& Adult & 1 & 1.0 & 1.8 & 100.0 \\
Missing & Total & 57 & 57.0 & 100.0 & \\
Total & System & 43 & 43.0 & & \\
\hline
\end{tabular}




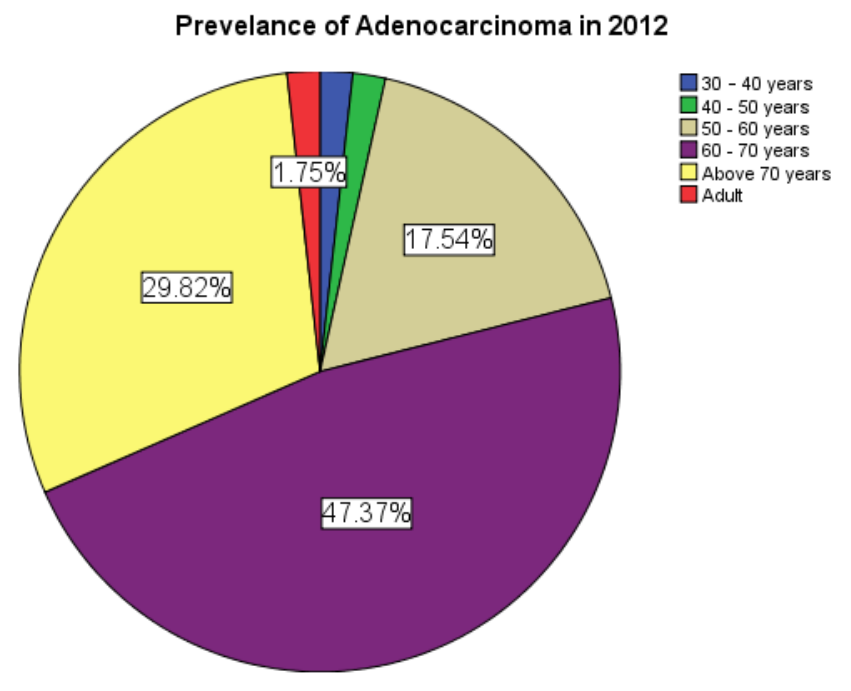

The overall result showed age range of 60-70 years as the most vulnerable age affected. They appeared to be at the peak in all the years of the study; leaving the age range of greater than 70 years as the next age of affectation. This is followed by age range of 50-60 years. Surprisingly, we still see age range of 40-50 years in three places of the year of study respectively as in 2010, 2011 and 2012. This is despite the fact that most scholars/studies believed that the disease often occur in the older age group only.

\section{Discussion/Conclusion:}

A total of 330 histologically diagnosed adenocarcinoma of prostate were seen with age ranges. The surprisingly results are patients seen with the lesion at age range of 40-50 years in 2010, 2011 and 2012. This goes to imply the asymptomatic nature in most patients;only incidental findings as those patients come with haematuria with obstructive symptoms. In other cases may be due to ignorance of the disease as the present late when the lesion is already advanced. ${ }^{16}$ This age range affectation is also seen in a similar study at Portharcourt, Nigeria where two cases $(1.0 \%)$ of ages $40-49$ years were seen by Obiorah and Nwosu in their study. ${ }^{17}$

The most vulnerable age range affected is 60-70 years as this appeared higher in all the year of study. This is closely followed by greater than 70 years. This is supported by other studies in this region of NigeriaPort Harcourt, ${ }^{17}$ Benin, ${ }^{18}$ Illorin, ${ }^{19}$ and Kano; ${ }^{20}$ all reported a high incidence in adenocarcinoma to the rate of $17 \%, 16.9 \%$ and $22.40 \%$ respectively. The high increase may be due to both genetic and environmental factors plus life style been emulated in most African nation-westernized aspect of lives these days. Also there is gross ignorance and lack of awareness which may be a factor hence prostate cancer screening and serum PSA test is still unknown among most populace. The need of media houses/electronic media awareness should be encouraged by the government plus free treatment centre as seen in most developed nation accessible to all citizenry. These will go a long way in getting better prognosis and longevity of such patients.

A good knowledge of the biology of tumour as per metastasis will help in early detection with combination of rectal examination, transurethral scan and serial serum PSA as a diagnostic tool.

\section{Acknowledgement}

We appreciate the contribution of the record staff of the Departmentof Pathology for uploading the results and the statistician Engr. Anthony Anaedu.

CONFLICT OF INTEREST: There is no conflict of interest among the authors.

AUTHORS DETAILS: Dr Martin Nnoli,Consultant Anatomic \& Forensic Pathologist. University of Calabar Teaching Hospital, Department of Pathology \& Forensic Medicine. Calabar.Cross-River State. Nigeria.

Dr AyodeleOmotoso, Consultant Anatomic Pathologist. University of Calabar Teaching Hospital, Department of Pathology \& Forensic Medicine. Calabar, Cross- River State. Nigeria.

Dr Victor Nwagbara, Consultant. University of Calabar Teaching Hospital, Dept of Surgery. Calabar, CrossRiver State. Nigeria. 


\section{References}

[1] Boyle P, Ferlay J: Cancer incidence and Mortality in Europe,2004. Am Oncol 2005,16:481-488.

[2] Delong Champs NB, Singh A, Haas GP: Epidemiology of Prostate Cancer in Africa: another step in the understanding of the disease? CurrProbl Cancer 2007,31(3):226-36.

[3] Haas GP, SakrWa. Epimemiology o Prostate Cancer J Clin 1997;47:273-87.

[4] Clement R: Prostate carcinoma medicine clinical references,drug references section 2 of 11 Article last updated 2007.

[5] Ojo SO, Rufai OA: Observation on the Pathology of incidental Carcinoma of the prostate gland in Nigerians. Orient Journal of medicine 1993,5(2and 3).

[6] Adamson AS, Francis JL, Witherow RO, Snell ME: Coagulopathy in the prostatic Cancer patient: Prevalence and clinical relevance.Ann R collSurgEngl 1993: 75-100.

[7] CalleEE,Rodriguez C, Walker Thurmond K, Thun MJ: Overweight,obesity and mortality from Cancer in a Prospectively studied Cohort of US adults. N Engl J Med 2003,348: 1625 -1638.

[8] Freeland SJ, Banez LL, Sun LL, Fitzsmons NJ, Moul JW: Obesse men have higher grade and Larger tumors: an analysis of the duke prostate center database. Prostate Cancer Prostatic Dis 2009,12:259 -263.

[9] Cheng L, Darson MF, Bergstrath EJ, Slezak J, Myers RP, Bostwick DG: Correlation of margin status and extraprostatic extension with progression of prostate Carcinoma. Cancer 1999,86: 1775- 1782.

[10] Van Roermund JG, Hinnen KA, Tolman CJ, Bol GH et al. Periprostatic fat correlates withtumor aggressiveness in prostate Cancer patients. BJU unit 2011,107: 1775 - 1779

[11] Fusley DS, Calvet VS, Inokuchi J, Lan A et al. Periprostatic adipose tissue as a modulator of prostate cancer aggressiveness. J urol 2009,182: $1621-1627$.

[12] Ribeiro RJ, Monteiro CP, Cunha VF et al. Tumor cells educated Periprostatic adipose tissue acquires an aggressive cancerpromoting secretory profile. Cell Physical Biochem 2012,29:233 - 240.

[13] RibeiroR,MonteiroC,Cunha V et al. Human Periprostatic adipose tissue promotes prostate cancer aggressiveness in invitro. J ExpClin Cancer res 2012. 31- 32 .

[14] Http://www.Cancer center. Com/home/90/Prostate/Prostate 2.cfm.[ last accessed in 2013].

[15] Nicolas B, Delong Champs, Amar Singh et al. The Role of Prevalence in the diagnosis of prostate cancer. Cancer control July 2006,vol.13,158-168.

[16] OluwabunmiEO,EmeO,Modupe L. Knowledge and awareness of Prostate cancer in men than $>>40$ years in Ibadan South western Nigeria. UICC world cancer congress July 9,2006.

[17] Obiorah CC, Nwosu SO. A Histopathological study of carcinoma of the prostate in Port Harcourt, Nigeria.Nigeria Journal of Clinical Practice.July - sept. 2011. Vol. 14. Issue 3.

[18] 18.Akang EE, Aligbe JU, Olisa EG: Prostatic Tumors in Benin City, Nigeria. West Afr Med 1996,15(1):56-60.

[19] Dawam D, RafindadiAH,Kalayi GD: Benign Prostatic hyperplasia and Prostatic Carcinoma in native Africans. BJU unit 2000,85(9):1074-7

[20] Yawe KT, TahirMB,Ngadda HA: Prostate Cancer in Maiduguri. West Afr J Med 2006,25(4):298-300.

[21] Yu KK, Scheidler J, HRicak H et al. Prostate Cancer: Prediction of extracapsular extension with endo rectal MR imaging and three dimensional proton MR spectroscopic imaging. Radiology 1999:213:481-8.

[22] Babin RJ, Mettlin C, Kane R, Murphy GP et al. The relationship of Prostate -Specific antigen to digital rectal examination and transrectal ultra sonography: Findings of American Cancer Society National Prostate Cancer detection Project. Cancer 1992;69:1195-200. 